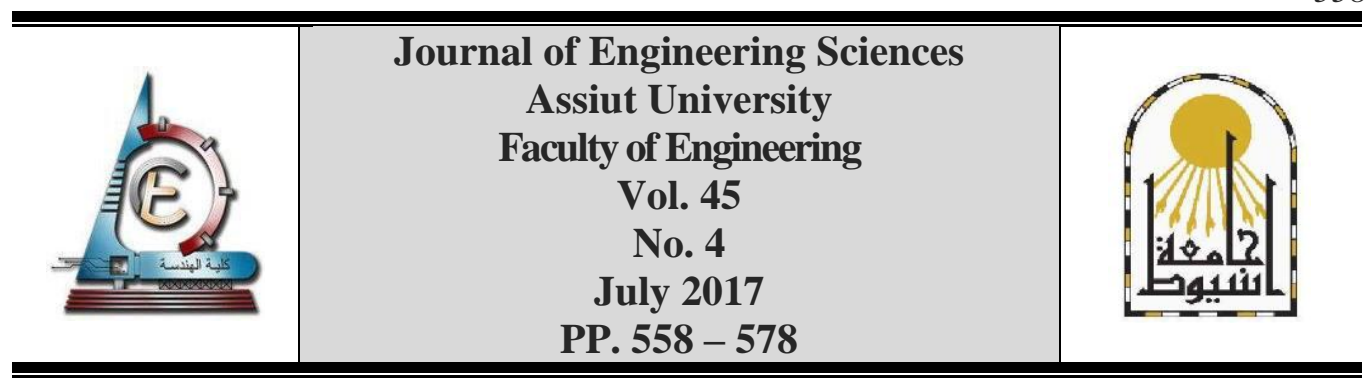

\title{
THE IMPACTS OF NEIGHBORHOOD LAND-USE PATTERNS ON RESIDENT'S SATISFACTION AND PERCEPTION TO SUSTAINABLE URBAN DEVELOPMENT: A COMPARISON OF FOUR NEIGHBORHOODS IN GREATER CAIRO REGION - EGYPT
}

\section{Islam Ghonimi Ibrahim}

Department of Architecture, Shoubra faculty of engineering, Benha University

Received 5 May 2017; Accepted 10 June 2017

\begin{abstract}
The debate of mixed versus separate land-use communities still constitutes a controversial matter for different interest groups. A growing number of scholars agree that neighborhoods with mixed compared to separate land-use could achieve sustainable development. On the other hand, residents and practitioners defend neighborhoods with separate land-use where residents can find calm, safety and open greenery spaces. On the other hand' Egyptian authorities fluctuates between promoting and restricting mixed versus separate land-use. Based on a case study in greater Cairo region (Egypt), the research poses to analyze and document the impact of land-use pattern on resident's satisfaction and perception of sustainable development; with reference to their socioeconomic level, and to explore the validity of such impact in Egypt. The case study was selected to be developed by the state and implies open public communities and not including private or gated property, to isolate any missleading satisfaction level.

The research found many contradictions and conflicts more than anticipated by literature review, before the start of the research. The research concluded a correlation between resident's satisfactions to the role of land-use on urban development and their socioeconomic Level. The analyses indicate that high-income residents' satisfaction to living in mixed-use neighborhoods more likely avoided based on key factors of environmental, social, and urban indicators; compared to low income residents' satisfaction, who found living in mixed neighborhoods more highly preferred based on key factors of functional and economic indicators.
\end{abstract}

Keywords: Mixed Vs. Separate Land-use Patterns, Residents Satisfaction, Residents income level, Development Indicators.

\section{Introduction}

Land-use pattern is an essential part of urban morphology of cities. A historical review of such reveals a continuous fluctuation of land-use pattern from traditional mixed land-use, followed by modern separate land-use, then revisited new post-modern trends of TOD, smart growth and new urbanism that retrieved mixed land-use. The type of adopted land-usepattern not only affects urban morphology but also affects achieved urban development. 
The idea of mixed versus separate land-use came under attack after 1970s. It still constitutes a debate between researchers, practitioners, residents and authorities. A growing number of researchers agree that separate land-use could impose negative impacts on urban development compared to mixed land-use. They argued that separate communities have destructive impacts on the long-term sustainability of cities. On the other hand' residents and practitioners criticized the negative impacts of mixed communities and defend the concept of separate land-use where residents can found calm, open greenery spaces. On the other hand' Egyptian authorities fluctuates between promoting and restricting mixed versus separate land-use in new initiated and existing transformed developments.

\subsection{Research aim:}

The aim is to assess the concept of mixed versus separate land-use communities and to evaluate their impacts on residents' satisfaction and perception of sustainable development; with specific reference to different involved study population, their perception, attitude, and behavior regarding the impacts of land-use pattern on sustainability. The aim is to test the validity of this in Cairo.

\subsection{Research hypothis:}

The paper hypothesized that resident's satisfaction of the efficiency of mixed land-use compared to separate land-use mainly influenced by their socioeconomic level and that current separate landuse urban form in new Egyptian cities rather than be solution for urban development it becomes part of the problem, It makes them less sustainable compared to traditional communities.

\subsection{Research method:}

A comparative analysis is used to test and compare the relation between land use pattern and resident's satisfaction and perception of urban development. The research depends on two interlocking stages. First, literature review to introduce the two variables of the research, land-use patterns in terms of concept, historical development, and measurable variables. In addition, to introduce urban development in terms of concepts, types and measurable indices. Finally, Field study for four neighborhoods in Greater Cairo Region to test the mutual relationship between the two variables. The field study go through three steps: Measuring pattern of land-use, measuring resident's perception of sustainable development indicators, and testing the validity of their relations. The research based on spatial model for measuring land-use pattern and Semi structured interview for measuring resident's satisfaction to urban development.

\section{Literature review:}

Scholars from various disciplines and practitioners all over the world are particularly interested in analyzing land-use patterns, types, measures, and their impacts on different dimensions of urban development. Numerous methodologies and frameworks are constructed to measure land-use patterns to build strong relation between land-use patterns and achieved urban development [1], others concerns to evaluate the effect mixed communities Impose on all dimensions of city and urban development. Some of which focus on their impact on Social Capital [2] [3], while others on urban life and livability [4]. Another group focuses on social sustainability [5], while others concerns urban development [6], and finally those on the measuring mixed vs. separate attitudes [7]. In this part an extensive literature review for three interlocking parts are documented. The first part handles mixed land-use in terms of the concept, historical development and 
reaching to its measurable variables. The second part handles theoretical review of the impacts of mixed versus separate land-use on urban development. The third deduce development indicators and its measurable indices.

\subsection{Land-use pattern and their measurement method: (separate versus mixed)}

Land-use pattern can be resembled in term of micro scale starting from block level, and neighborhood level to macro scale in city scale level. The scope of this research is concerning land-use pattern in neighborhood level. In this scales, the meaning of Land-use pattern can be explained regarding combination between residential units and other activities especially the one that are necessary for everyday life. It can be explained in terms of two extremes, separate land-use community, and mixed land-use community.

Mixed-use neighborhood mostly exists in traditional neighborhood, the one that contains all services mixed with residential areas and enables residents to perform daily activities without using private car. Many of these neighborhoods have services and facilities within walking distance. Complete or traditional neighborhoods encourage walking; residents pedestrians are forced to compete with cars along busy highways and to walk across expensive parking lots.

Separate land-use neighborhood mostly exists in new suburban neighborhoods, the one that contains only houses and services are gathered and separated from residential area. Some times daily needs are not met in the neighborhood or even in town; they are instead fulfilled at large megastores in malls or strip malls located at regional scale. If residents want to shop, they must travel by car to find services.

Many scholars searched for measures for land-use pattern [7] [8]. Our research concerns the spatial variables of land-use-pattern as main formation of urban form, and accordingly affects urban development. Land-use pattern is a spatial characteristic of neighborhood model. Size, shape and location of uses indicate the efficiency of landuse pattern. Landuse pattern is a working definition of neighbourhood landuse type, and forms the core of debate on mixed versus separate use and their impact on development. It can be classified under heading of landuse mix, variation and intensity. The (dividing vs. connecting) line between different land uses (residential and non-residential) represent the mixed vs. separation of land use define the pattern, as shown in Figure 1.

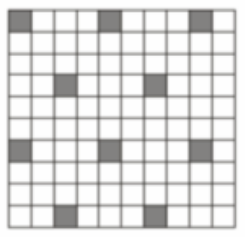

A

\begin{tabular}{l|l|l} 
X1 & $\begin{array}{l}\text { Land-use } \\
\text { mix } \\
\text { Factor }\end{array}$ & $\begin{array}{l}\text { It refers to length of connecting line between residential units } \\
\text { and services area, thelonger the length the greater the land use } \\
\text { mix. }\end{array}$ \\
\hline X2 & $\begin{array}{l}\text { Land-use } \\
\text { Variation } \\
\text { Factor }\end{array}$ & $\begin{array}{l}\text { It refers to area ratio of commercial, industrial, and publicland- } \\
\text { uses in the neighborhood divided by the number of residential } \\
\text { units; the higher the ratio, the greater the land-use variation. }\end{array}$ \\
\hline X3 & $\begin{array}{l}\text { Land-use } \\
\text { Intensity } \\
\text { Factor }\end{array}$ & $\begin{array}{l}\text { It refers to area ratio of sum area of non-residential land-use } \\
\text { types to area residential land-use type; the large the ration the } \\
\text { greater land-use intensity. }\end{array}$
\end{tabular}

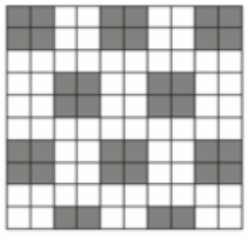

C

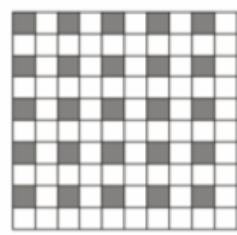

B

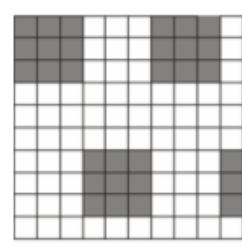

D

$$
\text { 西 }
$$


2.1.1 Historical background (mixed vs. separate) communities in Egypt:

Land-use pattern in Egypt passed through different stages and paradigm shifts. It reflects fluctuation between mixed land-use in traditional cities, and separate land-use in modern city, then a transformation from separate to mixed land-use with common orientation to separate land-use in new communities. Mixed-land-use district is an ordinary attribute for the majority of Egyptian cities [11]. The spread of commercial uses along circulation spines and among residential uses is a normal aspect for conventional Egyptian cities [11].

Separate-land-use district is a foreign attribute for new communities' wave; the pioneers who learned in the western world have translated this pattern to Egypt, in a process of westernization. This foreign idea introduced practical and scientific methods of planning that did not emerge from traditional processes [12]. It provides an alternative based on criticism of disadvantages of mixed-land-use that have spread in all over traditional communities. Almost all plans of new cities based on modern theories of master plans where residential districts are designed with segregated land-use pattern, of pure residential clusters, with all services separated in centers [13].

The concept separated-land-use are faced with different attetudes; first, most of the separate neighbourhoods that have been planned based on concept of central separate services like nasr city and new cairo has been gradually transformed into a different approach obeying mixed use specially across the main arterial roads. second, many compounds not only work to have separate services but also to remove services from consideration and replace them with facilities. third a new trend of new developments use postmodern mixed use patterns in new developments like Sodic East-town and Westtown.

\subsection{The impacts of land-use pattern on sustainable urban development:}

Neomerous theoretical reviews presents numerous methodologies and frameworks that are constructed to evaluate the effect imposed by types of land-use on urban development. Since 1960, worldwide case study research shows a contradicting orientation for the idea of mixed communities. Most of the committee's among which, sustainable residential neighborhood, smart growth, livability, and healthy communities agreed that mixed communities is a basic principle of creating cohesive communities. Mixed-use derives from core aspects of the urban sustainability agenda.

International making cities livable (IMCL) conference discusses ideas about livable places, its choolars Found mixed use, multi-functional public places, as well-functioning of public realm - meetings, encounters, dialogue among people young and old with a diversity of backgrounds, acquaintances, friends and strangers [14].

American Institute of architecture (AIA) and Agenda of Urban task force developed Ten general design principles for creating a livable communities, among them to encourage Mixed-use development: Integrating different land-uses and varied building types creates vibrant, pedestrian-friendly, and diverse communities. [15].

New Urbanism (NU) strives to build communities that promote mixed-use developments and pedestrian-friendly designs, attempt to build a sense of community via integrating private residential space with surrounding public space, to affect the formation of social networks and forms of interaction between residents and norms of reciprocity and trustworthiness. 
The Habitat's Program for Sustainable Cities (UN) promoted mixed use as a tool for achieving sustainable city in social, economic and physical development made to last. In term efficiency in using energy, water, and other resources minimization of required inputs of energy, water, protecting occupant health, Reducing waste, pollution and environmental degradation waste output of heat, air pollution.

Salingarous criticized contemporary separate land-use compaired to traditional mixed land-use, for not having the same degree of interconnections and accordingly discourage urban life, movements and interactions, they are disconnected in a separate sense [16]. Peter Calthorbe recommended that single-use zoning should be replaced with standards for mixed-use and walkable neighborhoods [17].

Jacobs exposed the importance of vitality of city, by focusing on the importance of the diversity into the city's streets and district. She rewuire district and as many of its internal parts as possible, must serve more than primary function, preferably more than two. She found that mixed use has the potential to attract more pedestrian activity, increase social interaction, and thus restore a richer, more vibrant, and more diverse urban life. She thinks that fine-grained mixed use is a crucial component of urban vitality was perhaps the first in a series of powerful critiques [4].

Most of them found mixed use as abundant with life, compact short distance buildings, services are in walking distance, livable public domain with commercial axis. They found mixed communities functionally and socially sustainable.

\subsection{Sutability to Egyptian Context:}

Mixed use is a spontaneous response for a series of social arrangements (Bardaa 1992). It is common in traditional districts to encourage people to live and feel satisfaction through gathering, collecting and mixing people and their requirements and activities into one place or in Arabic "lama" [18]. Egyptian people often prefer streets, buildings and neighborhoods that are abundant with life and activities and thus safe, whereas spaces that are not inhabited or used by people are seen as unsafe. Accordingly, people believe that mixed uses support their neighborhoods in being safe and full of activities or in Arabic "Wanass" [18].

According to Ghanamm [18], Egyptian people prefer "Wanas" that refers to people preference of having streets, buildings, and neighborhoods that are abundant with life and activities, thus be safe over those quit, empty, not inhabited or used by people thus scary and unsafe areas, just like streets at night. Thus Egyptian people believe that mixed uses support their buildings, streets, neighborhoods and city to be safe and full of life [11].

\subsection{Sustainable Development Indicators:}

After the previous literature review on the subject of land-use patterns and their relative impacts on development, the research found achieving sustainable development rests on five easy-to-investigate indicators: urban, functional, social, economic, and environmental indicators [19] that will be investigated by resident's satisfaction.

\subsubsection{Urban and visual indicators: (U.I)}

Urban and visual satisfaction indicators can be investigated in terms of questions regarding pedestrian movement, way finding, urban diversity and choices [20].

Ur1 Pedestrian movement

Ur2 Diversity and
It refers to make streets and urban spaces easy, safe, and pleasure, safe, livable pedestrian network, and urban spaces movement network [21].

It refers to create change and diversities to achieve pleasure, choices, 
choices support diversity in character, and to localize facilities and services [22].

Ur3 Variety It refers to achieve range, variety and choices of activities, uses, people, building types, forms, and urban spaces to create a range of meanings and in turn the meanings may influence the variety of options available [23], [4].

\subsubsection{Functional Indicators: (F.I)}

Functional satisfaction indicators can be investigated in terms of questions regarding low traffic cognition, sufficient provision of parking requirement, efficient movement behavior, short distance low frequent trips, and effecient and sufficient provision of services.

Fu1 Low frequent It refers to avoid isolating people without vehicles, create efficient "day" short trips and "night" districts [24].

Fu2 Alternative It refers to encourage potential for alternative transportation options and movement alternative movement systems (pedestrian, cycling, public transport) [25].

Fu3 Services It refers to efficient qualitative provision of services, to provide wide range provision of diversity and choices, variety and mix of services and facilities. [4].

Fu4 Streets It refers to achieve low traffic cognition [26]. efficiency

Fu5 Parking Lot It refers to achieve Sufficient provision of parking requirements [26].

\subsubsection{Social Indicators: (S.I)}

Social Satisfaction indicators can be investigated in terms of questions regarding Resident's interaction, sense of community, familiarity and trust in neighbors, and Safety and security.

So1 Residents It refers to achieve shared public facilities, services, public spaces, interaction transportation options, walking, and other facilities to encourage promote opportunities of amounts and types of residents human activities with i.e. walking, sitting, doing commercial exchanges, making pictures on a sidewalk, talking [27].

So2 Sense of It refer to increase resident feeling of membership, influence, integration, community fulfillment of needs, shared emotional connections; shared values, norms, meaning, and identity; stewardship, responsibility, and regard for neighbors and entire community[28].

So3 Public It refers to encourage residents' willingness to co-operate for mutual benefit, Familiarity, everyday type of social interactions; to foster trust, harmonious and coTrust and Reciprocity

So4 Safety and operative behavior needed in neighborhoods. [28]. security

It refers to crime reduction, displacement of crime and response time; to make continuous eye on streets, to being safe during walking trips from crime and attack; to be secured from traffic accidents; and to enhance personal safety and pedestrian/vehicle conflict [29].

\subsubsection{Economic Indicators: (Ec.I)}

Economic satisfaction indicators can be investigated in terms of questions regarding reduction of commuting cost, reduction of travel distance and reduction resource consumption.

Ec1 Economic It refers to provide residents with great economic opportunity for mutual interaction exchange between different adjacent and diverse parts to support opportunities for economic exchange [4].

Ec2 Reduce It refers to reduce travel distance, and provision of alternative transportation commute cost options that accordingly reduce commuting cost [30].

Ec3 Reduce resource It refers to spends less of resident's income on the combined cost of housing and consumption transportation; it provides residents with great number of transportation options [30]. 


\subsubsection{Environmental Indicator: (E.I)}

Environmental Satisfaction indicators can be investigated in terms of questions regarding reduction of air pollution, reduction of noise pollution, and reduction of fuel consumption.

En1 Fuel

Consumption

It refers to reduce vehicle miles, frequent trips, and depend on alternative

Reduction

EN2 Air pollution It refers to discourage travel energy movement systems; match projected Reduction $\quad$ o2 emission with tree planting. Control private motorized transport and give public transport priorities [32]

EN3 Noise Pollution It refers to facilitates walking and biking, lowers vehicle miles travelled, Reduction improves air quality, and enhances urban aesthetics [32].

\section{The case study of four neighborhoods in Cairo}

Cairo is exposed to different dramatic shifts in neighbourhood landuse models. Starting from traditional mixed-land-use, followed by modern separate-land-use, and followed by transformtion from separate to mixed land-use. The case study of Cairo will be investigated regarding the effect of landuse pattern on residents satisfaction in neighborhood scale [10]. In order to achieve this aim, the research depends on a field study, practical measurement and statistical analysis. The field study will go through three stages to achieve these goals.

\subsection{Case study selection criteria:}

Four neighborhoods were selected to present contrasts of physical and social attributes including the historical development, as shown in Figure 2. They should satisfy variables incorporated within the proposed model:

1. They should meet two chategories, the first that originally developed as separate land-use and transformed to current states of mixed land-use to meet resident's needs. And the second that originally developed and still working as separate landuse pattern due to the strict regulations of state.

2. In each category, two case-studies were selected to present high and low socieconomic levels.

3. Finally they should be built, occupied and of equal area.

4. The selected cases should be developed by the state and implies open public communities and not including private or gated property.

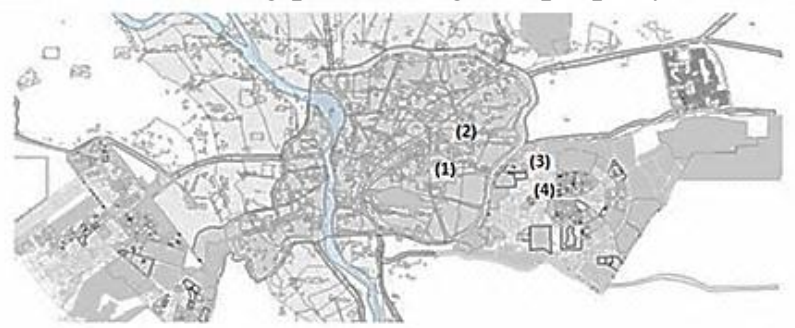

\begin{tabular}{|c|c|c|c|c|}
\hline & \multicolumn{2}{|c|}{ (A) Nasr City } & \multicolumn{2}{c|}{ (B) New Cairo } \\
\hline & NH 1 & NH 2 & NH 3 & NH 4 \\
\hline Name & Zahraa district & Dawod district & $1^{\text {st }}$ district & Yassmin district \\
\hline Date & 1980 & 1980 & 1990 & 1990 \\
\hline Income Level & Low and Mid & High & Low and Mid & High \\
\hline Land-use & \multicolumn{2}{|c|}{ Separate to Mixed } & \multicolumn{2}{c|}{ Separate } \\
\hline
\end{tabular}

Fig. 2. Case Study Selection (Greater Cairo Region) 
In type (A) two neighborhoods in nasr city are selected as originally planned as separate-land-use and transformed into mixed land use, where residents worked informally to transform urban form to mixeduse. the first low-income and the other for high income.

NH (1) Zahraa - Nasr city is a 40 years old community, one of the low and mid income level communities, that is developed by the state based on medium rise mid-density. It is original plan developed as modern separate land-use neighborhood. Gradually, ten years later it has been transformed by residents from original separate land-use pattern to mixed land-use. A dominant commercial mixed land-use axes are formed, with increasing their mix, variation and intensity, with inclusion of varity of commercial, educations, medical uses that are highly mixed with residential area to meet resident's needs.

NH (2) Dawowd Zawahri - Nasr City is a 50 years old community, one of the highincome level that is developed by the state based on medium-rise high-density. Its original plan developed as separate land-use neighborhood. Gradually, ten years later, its services pattern has been transformed to mixed, intensive and variation. Many of residents changed their occupation and migrated to other high-level communities, and left the place for those residents whose workplace is there, to resides there.

In type B, two neighborhoods in New Cairo are selected as originally planned and still working as separate-land-use. The first developed for low and mid-income and the other developed for high income. The strict regulation make them still working in the same manner it was planned without transformation.

NH (3) 1st district - New Cairo: 1st district - New Cairo, a 30 years old community is one of the low and mid-income level neighborhoods that is developed by the state based on mid-rise and mid-density. Its original plan developed as separate land-use pattern, where services are placed at central location separate from residential area.

NH (4) Yasmin district - New Cairo: Yasmin district - New Cairo, a 30 years old community is one of the high-income level neighborhoods that are developed by the state based on low-rise and low-density. Its original plan developed as separate land-use pattern, where services are placed at central location separate from residential area.

\subsection{Data Collection and Classification:}

The purpose is to measure the correlation between Land-use pattern and resident's perception and satisfaction to urban development in reference to their socioeconomic level. Two forms of data were collected, the first aims to measure land-use patterns and the other aims to measure resident's satisfaction to urban, functional, social, economic, and environmental aspects of development in their neighborhood. Finally, the correlation between both is measured.

\subsubsection{Neighborhood land-use pattern:}

Land-use data were collected using surveying maps, to document land-use pattern and to trace the modified land-use pattern according to resident's needs. Land-use pattern are gathered, measured and scored in Table 1. 


\section{Table 1.}

A comparison of original and modified land use plans for selected neighborhoods

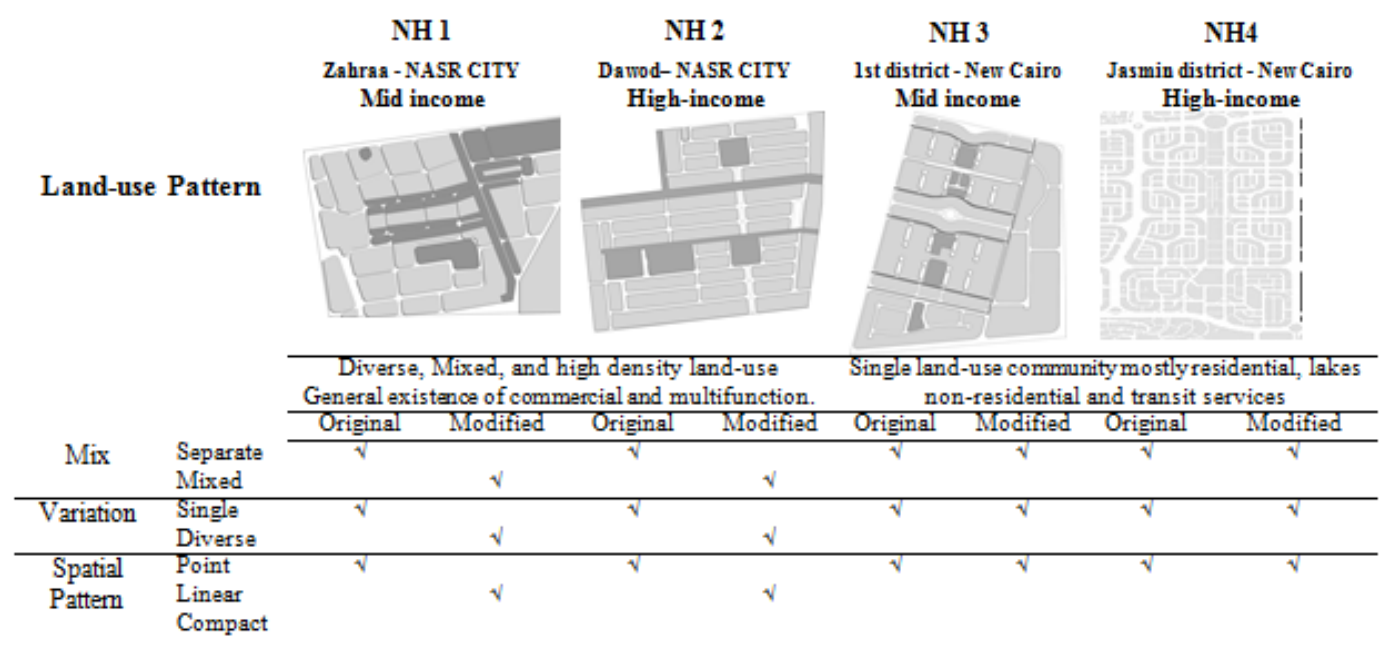

\subsubsection{Residents Satisfaction and perception of development indicators:}

Attitude measurement semi-structured interviews were conducted to 20 interviewees in each neighborhood over a total period of two months. The interviewees were selected to present different income level (High and Low), male and female are selected. The interview were designed to explore and collect qualitative data regarding resident's satisfaction to different development indicators. The purpose was to define the statically significant differences in satisfaction level between high and low income residents in mixed-use and separate-use neighborhoods. The questionnaire is formulated on the fivepoint Likert scale (scored from 1 to 5). It includes questions about:

5. Residents socio economic characteristics and car ownership.

6. Residents Urban satisfaction to pedestrian movement behavior, and alternative transportation option, way finding and diversity of urban form.

7. Functional satisfaction to traffic cognition, sufficient provision of parking requirement, efficient movement behavior, short distance low frequent trips, and efficient and sufficient provision of services.

8. Social Satisfaction to interaction, sense of community, reciprocity, familiarity and trust in neighbors, and Safety and security, and feeling safe and secure for their family, kids and wifes to move in the community.

9. Economic satisfaction to living cost in term of commuting cost, reduction of travel distance and reduction resource consumption.

10.Environmental Satisfaction to reduction of air pollution, reduction of noise pollution, and reduction of fuel consumption.

The interview results are gathered, measured and scored with degree of satisfaction and perception of sustainable development in percentage, in Table 2. 
Table 2.

Residents Satisfaction of development indicators (Percentage).

\begin{tabular}{|c|c|c|c|c|}
\hline \multirow{2}{*}{$\begin{array}{c}\text { Assesment } \\
\text { Factors }\end{array}$} & NH1 & NH2 & NH3 & NH4 \\
\cline { 2 - 5 } & Mixed landuse & Mixed landuse & Separate landuse & Separate landuse \\
\cline { 2 - 5 } & Low income & High income & Low income & High income \\
\hline Urban & $70 \%$ & $40 \%$ & $40 \%$ & $90 \%$ \\
\hline Functional & $90 \%$ & $10 \%$ & $10 \%$ & $70 \%$ \\
\hline Social & $70 \%$ & $20 \%$ & $30 \%$ & $90 \%$ \\
\hline Economic & $90 \%$ & $60 \%$ & $10 \%$ & $50 \%$ \\
\hline Environmental & $70 \%$ & $10 \%$ & $40 \%$ & $90 \%$ \\
\hline
\end{tabular}

\subsection{Analysis, result and discussion:}

In this part, a discussion using Interactive graph based on a comparison between data collected for each case study. The neighborhoods are presented from the higher mixed land-use communities $\mathrm{NH} 1$ to the higher in separate land-use community $\mathrm{NH} 4$. The theoretical Expectation is presented to achieve higher expected development with highly mixed neighborhoods (NH1), and presented to achieve lower expected development with lower Separate neighborhoods (NH4). Resident's Satisfaction curves are compared with regard to residents income level.

\subsubsection{Visual and urban aspects:}

Figure (3) reveals contradicting satisfaction level of low and high income residents for moving from mixed to separate communities. Which can be explained as follow:

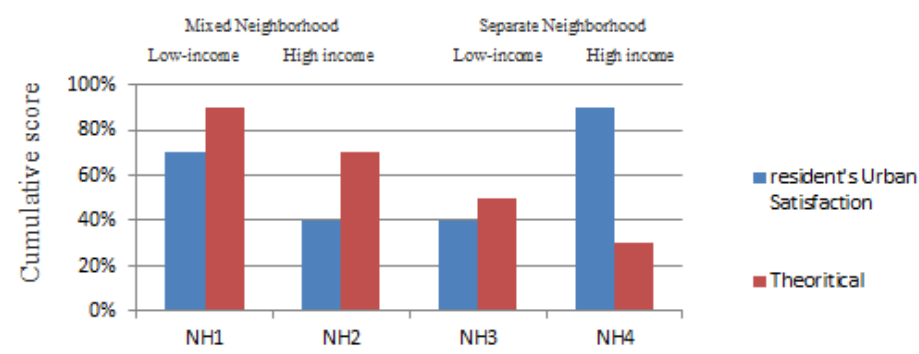

Fig. 3. Resident's satisfaction to urban development Indicators (Percentage)..

High-income residents conflict with theoritical expectations, they found moving from mixed to separate landuse neighbourhood increase their satisfaction to urban development. As stated by one of residents:

"We escape from dense concentration of people and low spaces, low green areas and low urban beutification, we miss our right for high standards of open green spaces. We miss similar unified character for our residential buildings with excluding the crowded visual polution of commercial advertising changing coloures images".

On the contrary, They highly prefere their separate landuse communities that provids appropriate high quality open spaces, calm, and greenery of streets and urban spaces, that promotes movment behavior and walkability and bycicle. Besdie, they found their neighbourhood reduce dense concentration of people accordingly provide calmnees. They have external paid input, they can afford the cost of green spaces and others.

On the Other hand, Low income Residents concide with theoritical expectations, they found moving from mixed to separate communities is less prefered. As stated by one of the residents: 
"Eventhough we found visual croudness in mixed communities but we found their Streets compine both residential and non-residential buildings, accordinlgy provides security and safty and implies diversity of activities, building types, hieghts and urban spaces accordingly they are more attractive for residents to promotes pedistrian movment behavior (walking and bycing). Their streets become and liviabile full of life. Beside we found defined identity and characheter in each region of the neighbourhood that enhance ligibility of orientation, you always know where you are".

On the contrary, They found separate landuse neighbourhood locate homes often at great distances from commercial areas, accordingly discourage walkabilty and increases car dependency. Besdie Streets are missing nonresidential uses, they lack security and livability, then they are not attractive, poore, and unsafe for pedistrian walkability. Besdie It makes them always miss the way since all building are similar in type, height, form, and function. As stated by one of the residents:

"You donot have dissimilar icons to distingush where you are, you need to ask different times to know where to go, some times you did not find persons to tell you where you are or how to get your target."

Our observation conflicts with residents perception. Our observation revealed a huge similarity of building types and low level of walkability in separate communities, beside ahuge disturbance in visual image in mixed communities.

\subsubsection{Functional Aspects:}

Figure (4) reveals contradicting satisfaction level of low and high income residents for moving from mixed to separate communities. Which can be explained as follow:

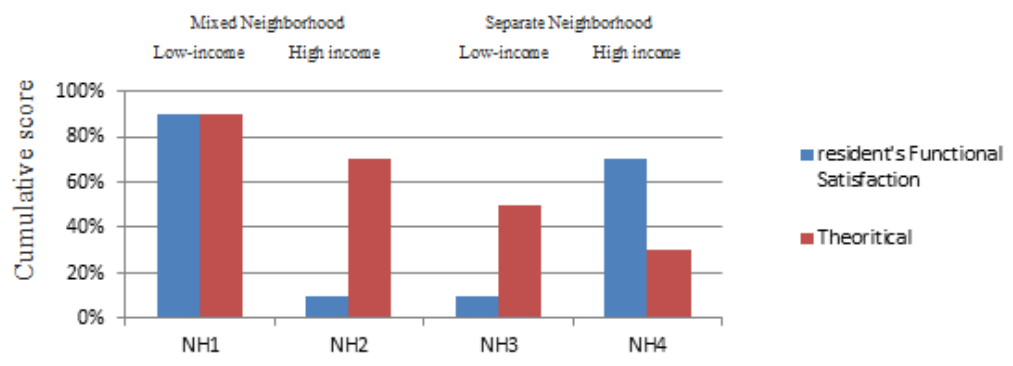

Fig. 4. Resident's satisfaction to functional development indicators (Percentage).

High-income resients conflect with theorities, they found moving from mixed to separate communities increase their satisfaction of functional development. As stated by one of the residents:

"Eventhough I found public transportation, but it is uncomfortable and did not meet my expectations, I donot have alternative to depend on private car, which ofcoure increase my norms of car ownership."

They found mixed communities share resdiential area streets and parking areas with services requirments, makes streets lack required parking lots, and make it crouded with high traffic cognition, unsafe for pedistrian. They have to use steel pars to keep their wright to have parking areas as soon as they come home. As stated by one of the residents:

"As soon as I come back home, it requires more than one hour to find a place to park my car, most of the residents uses steel par and put their name on it, to asure they have parking lane for them, and will not sufer to park their cars". 
They prefare separating services from resdiential area to avoid intrusions or passengers who can share them in parking area, and cause crouded traffic. To be sure they will have suffeceint car parking lots and effeceint streets with lower traffic and effeceint movment behaviour. At the same time they discourge public transportation and completely depend on alternative private car and high value of car ownership, accordingly it cause high traffic cognition, and accordingly, low effeceincy of arterial streets. As explained by residents:

"Living in new cairo is not practical without private car, to have any services or to go any where one take much time and distance, in case of car crash we donot have alternative to stay at home".

They do not worry for low sufficient provision of services or even public transportation; they mainly depend on private provision of goods. As stated by one of the residents:

"We do not need direct contact with services to have our goods, the life is changed. We go to hypermarkets and large mega stores. There is home delivery service, besides we have one or more car drivers who can go to large hyper market and get what we need".

Their priorities much more concerned to facilities, they have replaced public services with facilities and entertainment areas. They can afford the high value of private services, private car ownership, and high frequent trips. Beside they have servants who can cut far distance to super markets to bring required services, as explained by one of the residents:

"The public provision of services is not attainable and is not efficient and suitable, and that as the private alternative is better and satisfy our expectations, we do not care to bear its cost".

They have external money paid force, they afford the cost of private goods and private transportation. but in case of lake of this external force, they highly suffer from the negative impacts. Unlike the case of mixed communities they can handel their life.

On the contrary, low-income residents concide with theories; they found mixed-use neighbourhoods, provide all services especialy daily one within walking distance and avoid longer distances and consumption of more time to reach where they wish. It encourges public transportation and discourge private car deendency. Also it provides secure streets full of life that encourges walkability at any time of the day.

They found living in separate communities make it hard to get services, resedints are forced to move long distance and high frequent trips that consume more travel time, cost and effort to reach services. and since separate communities cause large distance areas with low density and low populated size, it could make alternative public transportation as unpractical solusion. As stated by one of the residents:

"If you cut long distance to the shoping market at separate services to puy breakfast and you forget cheese, you will have to get back and cut the same very long distance to consume more effort, cost, and propoably the morning time could be a problem to reach your children school bus at time, commuting cost of time, mony and effort is great in separate communities".

They are relativly more impacted with low services provesion, due to their low economic conditions, they can not afford cost of private car and private provesion of services. they are forced to depend on alternative public options. They lack the basic physical infrastructure. To conclude low-income Rsidents face a great problem in their movment behaviour in the city. 
Our Observation conflects with residents perception, it revealeas shortage in parking areas, high frequent long distance trips, high traffic cognition at main streets, and high traffic cognition at peak hours greater than traffic cognition that take place in old traditional cairo. As stated by one of the residents who argued that:

"At 8am, we found new cairo streets are very crowded more than it was the case in midtown of old cairo wher we come from".

Our Observation revealed a high value of car ownership ranges between two to three car lot per family, accordingly require large no. of parking lots, accordingly cause low effeceincy in meeting residents huge demand of car parking. Beside the residents found their car very essintial for living, As stated by on of the residents,

"If my car is break down or crashed, I face a very big problem with my working day. I have to stay at home untill I fix it, the car become a must."

As unexpected separate landuse communities compaired to mixed landuse communities rather than solve the problem of traffic cognition it become part of the problem. Actually, separate communities as unexpected cause high traffic cognition, and accordingly impact effeceincy of arterial streets.

\subsubsection{Social aspects:}

Figure (5) reveals contradicting satisfaction level of low and high income residents for moving from mixed to separate communities. Which can be explained as follow:

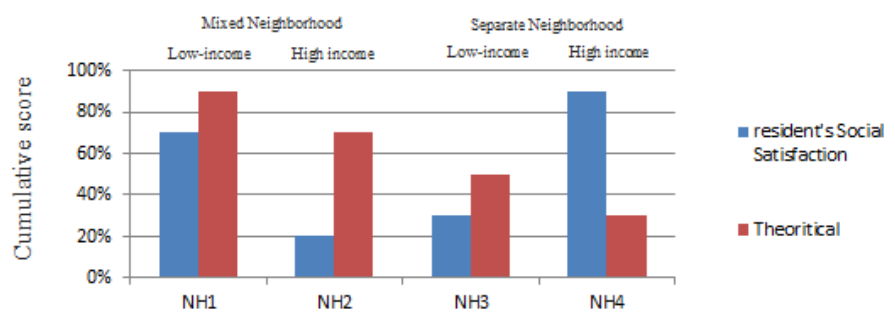

Fig. د. Kesident's satıstaction to social development 1ndicators (rercentage).

1- Interaction:

High-income resients conflect with theoritiies; they found moving from mixed to separate communities increase their satisfaction to interaction and trust. They found mixed communities includes services so it become unquit place and unsafe for its residents, spaces are full of unknown intrusions that reduces trust of others, accordingly they fair to know others and accordingly reduce interaction. As stated by one of the resdients:

"We want to exclude our children from streets, they should not interact with lowincome level to avoid learning bad attitudes, we keep them home as possible as we can".

On the contrary, they found separate communities promote interaction through neighboring familiarity, there is no intrutions or external passengers, only neighbours who exist in urban spaces; they mostly know each other, that provides local sense of community and identity. Beside they prefer rather than know neighbours from streets to know them in community social club where they can meet and socialize their young childern with similar socioeconomic level. Where they can encourage some kind of contraction, involvement and participation in micro community, as explained by one of residents: 
"We feel the intimate scale of the community, we feel ease of contact with each other, we build small civil society that contact with developer and are responsible for the community".

On the other hand, low-income residents concides with theories; they found mixed communities promote interaction, since they walk more so they meet neighbors in services area, accordingly increase the chances for meeting each other, they feel more connected to their community, accordingly, they are more likely to know their neighbors, are more likely to trust or have faith in other people and enhance the trust and reciprocity between resedints and accordingly enhance interaction between resedint. As stated by one of the residents:

"Streets is a place of our children to meet, interact, and exchange knowledge, we sense of lama and wanas in such a streets that are abondant of life".

On the Contrary, they found separate communities make streets as unwelkcoming for walkability and donot provide common areas, accordingly it reduces the chances for meeting their neighbours and knowing them. Beside, they donot have affordability to participate in any social club to give them self and their family the chance to interact and know heir community. They are far from knowing their neighbors, they fair to know their neighbors, and fair to trust them. This reduces the trust in evry thing even in the neighbours and discourge interaction between resedint. It reduces sense of trust and reciprocity between neighbours living inside this area. They found it not only isolate streets from through traffic but also from every thing else. It becomes an exclusive destination, it becomes only a place to go to rather than a place that might also passed through. Which diminishes by-product of movement, or the potentialities of other optional activities in adition to the basic activity of traveling from point to point; thus isolating and excluding those too young, old, and poor who can not drive.

Our Observation revealed that low level of social interaction for both low and high income residents, they donot know their neighbourhs, as explained by one of the low income residents:

"In old mixed neighbourhoods, where we come from, we know every one in the community. We always share our public life to meet in streets. on the other hand here, in separate landuse communities, we hardly know our nearst neighbours.

And as stated by another one of the high income residents:

"None of the residents have time to waste building the community relationships..., where everyone is a community in his own right."

\section{2- Safety and security:}

High-income residents conflect with theories, they found moving from mixed to separate communities increase their satisfaction of safty and security. They found mixed communities unsafe, they suffered from inclusion of services inside the residential area, they fair adjacency between services and their homes, they fair of intrusions, unwanted, unfamiliar, and fair of crowded traffics for their children. They thought that this cause a lack of safety and increase crime opportunities. They exclude their children from streets to avoid accidents and intrusions. On the contrary, they found separates communities provides quieter and safer streets and urban spaces, where children can play with minimal fear of fast moving traffic. It provides a sense of safety against intrusion and unfamiliar persons, and reduce the crime opportunities, they found safety through excluding the others. 
On the other hand, low-income resident concides with theory; they found mixed communities save and secure, since streets are livable abundant of live, a continuous eye on streets; and they found it secure for their children since there is no fast moving traffic. Residents know each other they also recognize strangers. The interaction and relationship between residents, mutual relationship with reciprocity, achieve safety inside streets. On the Contrary, they found separate communities reduce through movmennt of people so it cannot animate streets, it loses life, no eye observe streets all day and night; Accordingly, they are unsafe and enhances crime opportunity, by reducing through movment of people which Accordingly it reduces sense of safety. Beside it is not secure for their children.

Our Observation contradicts with resident's perception, High-income residents perceive separate communities as safe with high interaction, but actually high-income residents have external money paid force to have private security, they can feel save all day and night. But with lack of paid security due to their high cost or even due to instability of security gap conditions as an example, after the 25 jan revolutions, a security gap exist, it makes low and high-income residents feel unsafe in separate communities compared to mixed communities.

\subsubsection{Economic aspects:}

Figure (6) reveals contradicting satisfaction level of low and high income residents for moving from mixed to separate communities. Which can be explained as follow:

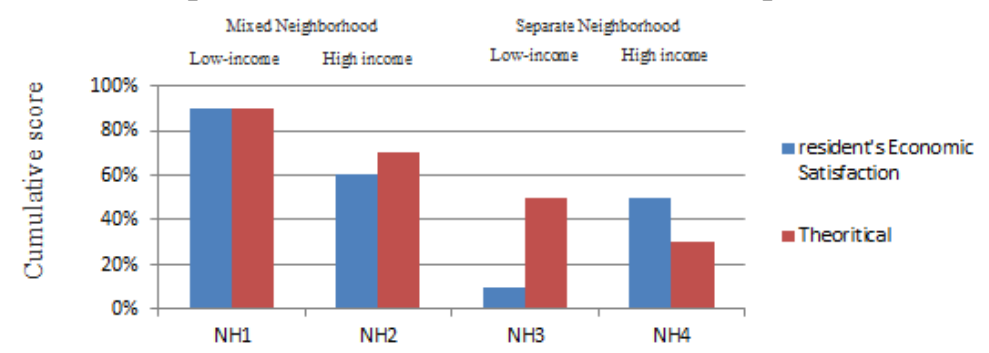

Fig. 6. Resident's satisfaction to Economic development (Percentage).

High-income residents concides with theories; they found living in mixed communities consume low living cost, but it does not meet their urban, functional, social expectations. So they do not worry to bear extra cost in separate communities. At the same time, they found separate-communities consumes high living cost, it incorporates large distances and high frequent trips, they consume high communiting costs, but they can afford, they can pay to have other urban, functional, social, and environmental benefits. They will shop from hyper market and will teach their children in international schools; according to their periorities' there is no essential need for mixed use with the residential area. As stated by one of the residents:

"we donot deny that in cases of fuel reduction, we suffer too much to live in separate communities we have to wait long time in every long lane to have fuel. Which of course due to high rate of consumption due to long distance frequent trips we suffer every day to have fuel compaired to other mixed communities who are low consumption and low car dependency".

On the other hand, Low-income residents, found living in mixed communities require lower living cost; they do not need to consume high commuting cost to reach services. Services are located within walking distance. They can use public transportation and walkability; they do not have to depend on private car. They found mixed communities enhance through movement and increase economic benfits on services, accordingly It increase economic interaction. On the contrary, they found separate land-use pattern 
consumes high living cost; homes are often located at great distances from commercial establishments, which further discourage walking and increases dependency on the private car. To have services, residents have to pay high commuting cost, and consume time and effort. They found it as expensive, they cannot afford. As stated by one of the residents,

They found high standards of car fuel consumption, time consumption, beside the cost of car mentance, and change rates of spare parts, every thing need cost more than we used to in mixed neighbourhoods, most of the residents face car faliur due to the unusual high rates of car use, accordingly high rate of car spares and motor oil change rates. We need two cars one for father and another for mother"

Our observation conflicts with resident's perception, we observed higher commuting cost, since it based mainly on private car with high value of ownership, high trips, long distance trips, the matter that impacts development. Beside, lack of fuel provision; and increase of fuel prices. As an example, after the 25 jan revolutions, low and high-income residents completely suffered not only from communing cost but also due to the required long waiting time in fuel stated by one of the residents:

Also incase of having diffeculties in having fuel due to increasing its cost or due to general lake of government provesion of fuels, we face big problem in separate communities, we donot have alternative public transportation other wise we have to bear extra cost and time ranges between 6 to 7 hours to have full tank and some times they cannot take ecxept half tanke ot 20 liter". It become more than an economic cost, it exceedes to be a matter of cost of time and behaviour".

This are combined with high consumption rates due to long distance and high frequent trips. High-income residents lose their external money paid force that eliminate from their own perception the negative impacts of separate communities.

\subsubsection{Environmental aspects:}

Figure (7) reveals contradicting satisfaction level of low and high income residents for moving from mixed to separate communities. Which can be explained as follow:

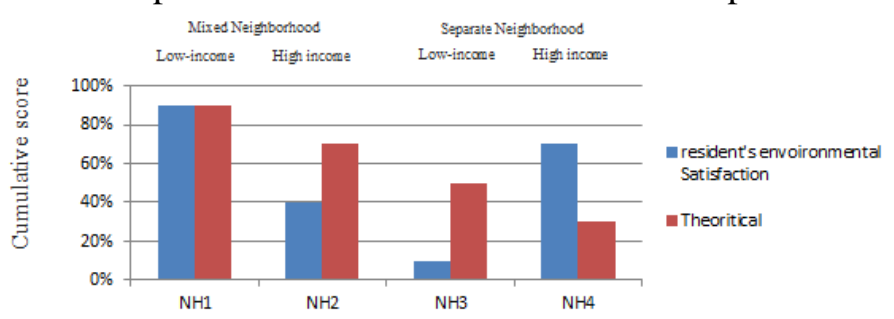

Fig.7. Residents Satisfaction to Environmental development (percentage).

High-income residents coflect with theories, they found moving from mixed to separate communities reduces pollution, as stated by one of the residents:

"We suffered in mixed land-use communities from noise as serious problem, noise from passengers, and noise from uses and other especially during night, accordingly it increases environmental and noise pollution.

They found separate communities promising solutions for avoiding noise pollution from passengers, uses and other especially during night, they found calm environment. They found solution for environmental pollution with perfect air quality sunny and clear environment. 
On the other hand, Low-income residents concedes with theories, they found mixed-use communities are much crowded and higher pollution, but it is pedestrian oriented, that reduce car dependency and accordingly reduce environmental and noise pollution caused by high frequent trips. They found Separate land-use communities are car oriented that increase car trips and traffic cognition during much of the day, and accordingly increase co2 emission, air pollution, increase fuel energy consumption. Accordingly, it increase environmental and noise pollution, and reduces un-renewable resource consumption due to the high-level fuel consumption. Our Observation conflicts with resident's perception, it revealed high rates of car consumption that cause high rates of noise and air pollution.

\subsection{General satisfaction of sustainability:}

Generaly, resident's satisfaction deviates from theoritical expectations based on housingincome level. Two sustainability evaluation criteria is deduced, the first sustainablety on perception level, and sustainablety on observation level.

Mixed use neighbourhoods are sustainable when it is measured on observation level. On the contrary when it is measured on perception level it records two contradicting evaluation in term of residents income level. High income residents found mixed land-use communities reduce their perception of sustainability in contrast with low income resdidents who found mixed communities sustainable on perception level.

On the other hand, Separate use neighbourhoods are not sustainable when it is measured on observation level. On the contrary when it is measured on perception level, it records two contradicting evaluation based on residents income level. Low income residents found separate communities decrease their overal satisfaction and perception of sustainability in contrast to high income residents who found separate use as sustainable on perception level.

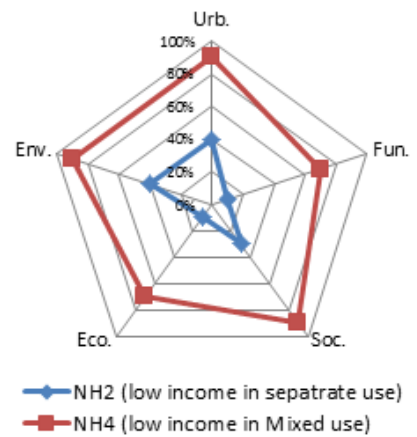

a) Low income redisents satisfaction

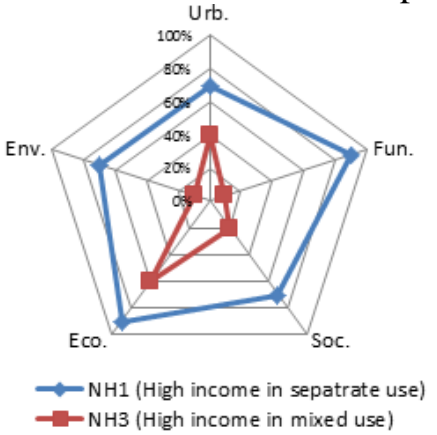

b) High income redisents satisfaction

Fig.8. Comparing satisfaction level for High and low income residents (in percentage).

Fig. 8 illustrates that low income residents consider economic and functional indicators are key factors for their evaluation of sustainability than social, uran and environmental indicators. On the contrary high income residents consider social, Urban, and Environmental indicators are key factors for their evaluation of satisfaction level than functional and economic indicators. This is because they have external monry paid input, they can afford cost of fixing functional and economic aspecst based on private alternative provesion.

In term of sustainability, Mixed use neigbourhoods compaired to separate use neighbourhoods seems to achieve high value in term of sustainability level. On the contrary, 
in term of satisfaction level, mixed use neighbourhood is highly prefered by low income level. And separate use neighbourhoods is highly prefered by high income residents.

\section{Conclusion}

This paper provides a brief documentation to the literature on land-use pattern, meaning, types, and measures, and their impact on urban development with their measures. It focuses on five easy-to-investigate indicators urban, functional, social, economic and environmental they used to evaluate land-use pattern in New Cairo Settlement (NCS), Egypt, with reference to residents perception.

This paper found that resident's satisfaction to development between mixed versus separate land-use neighborhoods was statistically insignificant when the effects of household income were incorporated. Most of the findings confirm deeper conflicts between theories, resident's perception and real observation.

In the first hand, the theoretical expectations generally suggest that mixed communities is positively affect development than separate communities. On the other hand, the interview revealed a conflict with theories; it revealed that residents' satisfaction mostly relates to their socioeconomic level.

In separate communities, resident's perception of development is directly proportional with their income level. In mixed communities, resident's perception of development is inversely proportional with their income level. Accordingly, adopted development criteria for measuring land use pattern cannot be the same; it needs to be revisited for different housing types:

- Residents with High-income explicitly resists land-use mix and relies on single landuse communities, mostly residential. They prefer separate land use neighborhoods that reduce dense concentration of people and provide calm and beatification of streets and urban spaces; compared to mixed land use communities that encourage dense concentration of people and reduce spaces, green areas and urban beatification.

- Residents with low-income level encourage and rely on mixed-use communities. They prefer mixed land use communities that reduce traveled vehicle miles and facilitate movement behavior and alternative transportation options walking and biking. It provides diversity of activities inside public life in the city, affecting its livability; it creates livable areas full of life. Compared to separate land-use communities that locate homes at great distances from commercial areas, which further discourage walkability and increases car dependence.

- Both of them found their preferred habits and attitudes, and can face the obstacles to achieve development. For Low-income residents the functional and economic indicators are key factors for measuring their satisfaction of development. For High Income residents, the visual, urban, social, and environmental indicators are the key factors for their satisfaction of development.

\subsection{Our observation conflicts with resident's perception, in different aspects:}

- In separate communities, although high-income residents perceive normal functional performance and moderate economic cost, we observed high rates of private car ownership, high economic cost especially in case of low resources and revolutions.

- Observation revealed a consumption of high economic and environmental cost in separate communities compared to mixed communities. 


\subsection{Recommendations:}

- The paper alerts the decision-makers and policy makers to revisit their orientation for mixed versus separate communities based on resident's income level.

- The planners should take in their consideration housing-income level when considering adopted land-use pattern, to create environment that encourage social interaction in the way residents used to do.

\section{REFERENCE}

[1] Paul Mitchell, Anne Vernez, and Miles G. Logsdon, "Measuring landuse patterns for transportation research," transportation research record, p. 17, Feb. 2012.

[2] Gehan Elsayed Abd Eldayem Noha Ahmed Nabil, "Influence of mixed land-use on realizing the social capital," Housing and Building National Research Center, vol. 11, pp. 258-298, March 2014.

[3] Levin Leyden, "Social Capital and the built environment: the importance of walkable neighbourhoods," American Journal of Public Health, vol. 93, no. 9, pp. 1546 - 1551, September 2003.

[4] Jane Jacob, The death and life of great american cities. New York: Ventage Books, 1961.

[5] Sarika Bahadure and Rajashree Kotharkar, "Social Sustainability and Mixed Landuse, Case Study of Neighborhoods in Nagpur, India ," Bonfring International Journal of Industrial Engineering and Management Science, vol. 2, no. 4, December 2012.

[6] R.S. Kotharkar and S.P. Bahadure, "Mixed Landuse, An approach to Sustainable Urban Development," in International Conference Urbanism and Green Architecture, Hamirpur, 2010, pp. 149-158.

[7] Yan Song, Kelly Clifton, and Reid Ewing Gerrit Knaap, "Seeing the Elephant: Multidisciplinary measures of urban sprawl," National Center for Smart Growth University of Maryland.

[8] G. Knaap, Y. Song, and R. Ewing, "Seeing the Elephant: Multidisciplinary disciplinary Measures of Urban Sprawl," National Centre for Smart Growth Research and Education, 2005.

[9] islam ghonimi, "neighbourhood socio-spatial manifestation of political regeme shift," in ISUF, 2014.

[10] Islam Ghonimi, "Neighbourhood models as a manifestation of political reigime paradigm shift: a case study of cairo-Egypt.," in sminar on urban form, our common future.

[11] Abdelkhalek Awad Ibrahim, "Egyptian Compact-City Veracity: The Fallacy and Credibility of Mixed Use and High Density for a Low Carbon City," in 45th ISOCARP Congress, 2009.

[12] A.-F.S. Shalaby, Transfer of Ideas through Planning Education in Egypt : The Case of the Spatial Form of Low Income Housing. Cardiff: Cardiff University, 2003.

[13] Asmaa Ibrahim, Index measuring the efficiency of applying the "mixed use" concept and its correlation with development. Cairo: A thesis submitted as a partial fulfillment of Doctor of philosophy in architecture, Cairo university, 2007.

[14] Talja Blokland and Mike Savage, "Social Capital and Networked Urbanism," in Networked Urbanism.: Aldershot: Ashgate, 2008.

[15] Bill Hillier and Julienne Hanson, The Social Logic of Space.: Cambridge. University Press., 1984.

[16] Nikos A. Salingaros, "The Fractal City," PLANUM -- The European Journal of Planning Online, March 2004.

[17] Peter Calthorpe, The Regional City., 2004.

[18] Farah Ghannam, Remaking the Modern Space, Relocation, and the Politics of Identity in a Global Cairo.: University of California Press, Berkeley., 2002.

[19] Islam Ghonimi, "Testing the validity of the impacts of Gated Communities on urban development," in The Future of Gated Communities, Building research centre., Cairo, Egypt, 2013.

[20] Leed-ND (2010) "A Citizen's Guide to LEED for Neighborhood Development: How to Tell if 
Development is Smart and Green", united states green building consul.

[21] URBED (1997) “The Model Sustainable Urban Neighborhood?” Sun Dial, Issue 4.

[22] Steele, F. (1981). The sense of place: CBI Publishing Company, Inc.

[23] Evans, G. L. (2001). Cultural planning: An urban renaissance? London: Routledge.

[24] Masnavi, Mohammad-Reza. 2000 "The New Millenium and the New Urban Paradigm: The Compact City in Practice." chapter in Williams, et.al (eds) Achieving Sustainable Urban Form. London: E\&F Spon.

[25] Engwicht, David. 1992. Towards an eco-city: Calming the traffic. Sydney, Australia: Envirobook.

[26] UN () "sustainable urban mobility"

[27]. Bentley I (1990) “Ecological Urban Design” Architects’ Journal, Vol.192, 24 October.

[28] McMillan, David W., \& Chavis, David M. (1986). Sense of community: A definition and theory. Journal of Community Psychology, 14, 6-23. Retrieved July 8, 2008, from Google Scholar.

[29] Landman, K. (2004). Gated communities in South Africa: The challenges for spatial planning and land use management. The Town Planning Review, 75.

[30] El-Zamly, H, A. (1994)., Arid Zones : A New Trend in Planning Education, 2nd international symposium ,Planning Education in the 21st century, Cairo University, Egypt.

[31]. Carmona M, Heath T, Oc T \& Tiesdell S (2003) Public Spaces Urban Spaces, The Dimensions of Urban Design, Oxford, Architectural Press.

[32] Newton, Peter. 2000 "Urban Form and Environmental Performance" chapter in Williams, et.al (eds) Achieving Sustainable Urban Form. London: E\&F Spon. 


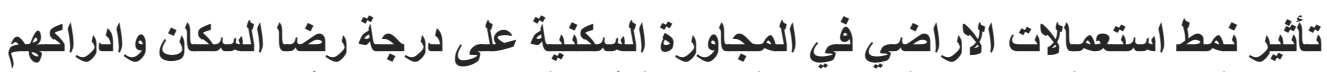

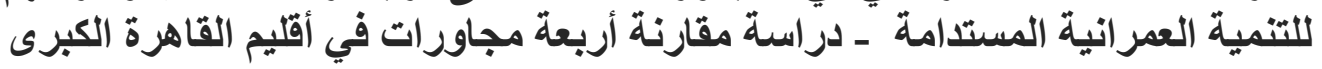

$$
\text { ملخص البحث: }
$$

يتجلى التناقض بين استخدام انماط الاستعمالات المختلطة و المنفصلة تمثل جدلية للعديد من الفئات المهتمة بالعمران. فقد أتفق العديد من الباحثين في مجال العمران على ان خلط الاستعمالات بالمقارنة بفصل

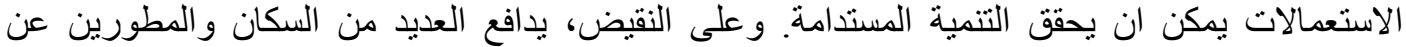

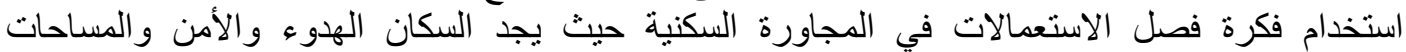

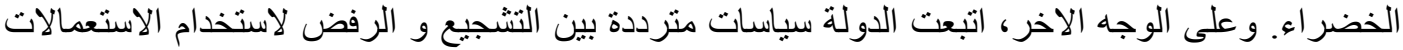

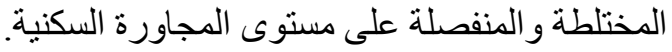

تعتمد الدر اسة على در اسة حالة في اقليم القاهرة الكبرى لتحليل وتوثيق تاثثير نمط استعمالات الار اضي اضي التي

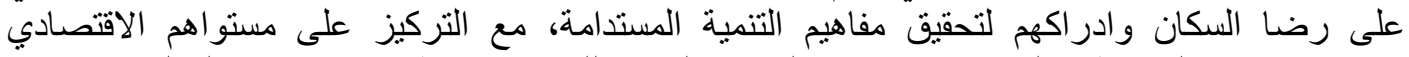

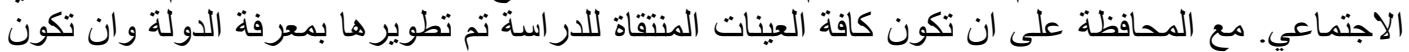

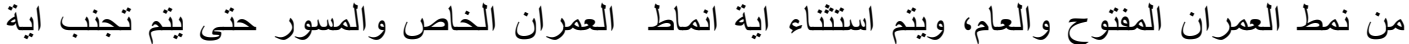

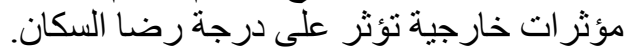

وقد توصل البحث للعديد من التناقضات التي تنتاقض مع النظريات والتوجهات الخاصة بالتنمية المستدامة. فقد اوضحت الدراسة وجود على بين المستوى الاقتصنادي الاجتماعي والاقتصادي للسكان وبين

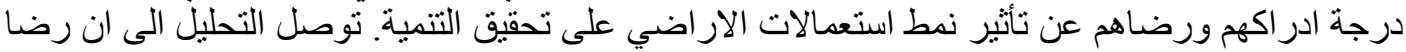

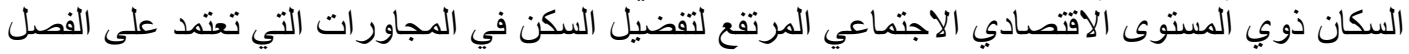

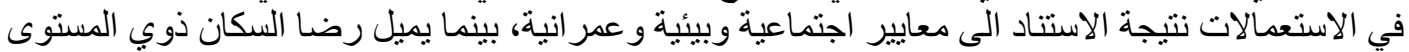

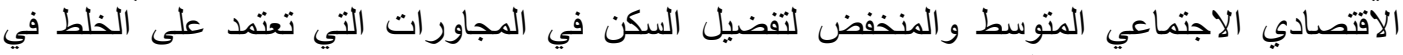
الاستعمالات نتيجة الاستناد الى معايير التتصنادية ووظيفية.

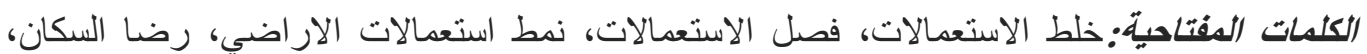
مستوى السكان تبعا للاخل، مؤشات التنمية العمر انية. 